\title{
Clinical Reasoning: A 59-year-old woman with multiple myeloma and lower extremity weakness and numbness
}

Ron Gadot, BSc, * Fábio A. Nascimento, MD,* Martha Mims, MD, PhD, and Karen Nunez-Wallace, MD

Neurology ${ }^{\circledR}$ 2020;94:794-800. doi:10.1212/WNL.0000000000009376

\author{
Correspondence \\ Dr. Nascimento \\ nascimento.fabio.a@ \\ gmail.com
}

\section{Section 1}

A 59-year-old woman with a history of stage 3 immunoglobulin G ( $\operatorname{lgG}$ ) lambda multiple myeloma (MM) on treatment with bortezomib and dexamethasone, chronic lower back pain, and chronic but improving bilateral lower extremity weakness and numbness presented with 2 to 3 weeks of worsening lower extremity weakness and numbness. Prior to presentation, the patient had been hospitalized for sepsis and cardiac arrest. Weakness affected the left lower extremity before progressing to the right lower extremity, whereas numbness was present in both feet. There was no bowel or bladder incontinence, saddle anesthesia, preceding trauma, or history of radiation therapy. The bilateral lower extremity weakness and numbness resulted in gait impairment and falls, which prompted admission for further investigation. Notably, bortezomib had been started 4 months prior to presentation.

Initial examination revealed cachexia, bilateral thigh atrophy, and bilateral lower extremity flaccid weakness, along with areflexia. The weakness was symmetric proximally (Medical Research Council $1 / 5$ in bilateral hip flexion and knee flexion and extension) but asymmetric distally $(0 / 5$ in right dorsiflexion; $2 / 5$ in right plantarflexion, left dorsiflexion, and plantarflexion). In addition to the weakness, the patient exhibited symmetric sensory loss in the distal lower extremities. There was no sensory level. Examination of the upper extremities was normal, including motor, sensory, and reflexes.

\section{Question for consideration:}

1. How can one localize the lesions?

\section{GO TO SECTION 2}

\footnotetext{
*These authors contributed equally to this work.
}

From Baylor College of Medicine School of Medicine (R.G.); and the Department of Neurology (R.G., F.A.N., K.N.-W.) and Section of Hematology and Oncology, Department of Medicine (M.M.), Baylor College of Medicine, Houston, TX.

Go to Neurology.org/N for full disclosures. Funding information and disclosures deemed relevant by the authors, if any, are provided at the end of the article. 


\section{Section 2}

The first step in localizing the lesion is to discern between upper and lower motor neuron involvement (table e-1, doi. org/10.5061/dryad.d2547d7zd). Based on the pattern of weakness, atrophy, and decreased reflexes and tone, one can localize the lesion to the lower motor neuron. The brain and spinal cord are therefore improbable locations. In addition, spine pathology is unlikely due to absent bowel and bladder incontinence and lack of a sensory level on examination. This diagnostic approach leaves the following possible topographies: anterior horn cell, nerve root, plexus, peripheral nerve, neuromuscular junction, and muscle.

\section{Lesion at the level of the anterior horn cell and muscle}

These topographies are unlikely to be the location of the lesion given the associated sensory changes accompanying the weakness.

\section{Lesion at the level of the lumbosacral plexus}

Dysfunction at the level of the lumbosacral plexus is a possibility, especially in the context of a known underlying malignancy. However, malignant lumbosacral plexopathy is typically unilateral, and these patients generally experience pain (more pronounced at night) before developing weakness, numbness, and diminished/absent reflexes. ${ }^{1}$ Also, if the patient had injury to the lumbosacral plexi, irrespective of the etiology, one would expect a more pronounced and asymmetric sensory pattern instead of solely distal lower extremity numbness.

\section{Lesion at the level of the peripheral nerve}

A peripheral nerve lesion is also a possibility. Within the realm of peripheral neuropathy, if only the distal sensory changes are taken into account, the patient presentation would fit a polyneuropathy pattern. If the patient had presented with asymmetric sensory symptoms along with asymmetric weakness, it would have suggested a mononeuropathy multiplex pattern.

Mononeuropathy multiplex, which describes the involvement of multiple noncontiguous peripheral nerves either simultaneously or serially, ${ }^{2}$ could explain the patient's asymmetric weakness if injury involved multiple peripheral nerves, such as femoral, peroneal, tibial, or sciatic. However, sensory changes would have involved the femoral distribution (anterior thighs and medial legs) and the distal lower extremity numbness would have been asymmetric. In this patient, the right peroneal nerve was more involved, as was evidenced by a weaker right foot, hence one would have expected corresponding asymmetric distal lower extremity numbness featuring exaggerated sensory changes on the right, which was not found. Moreover, mononeuropathy multiplex would likely have involved peripheral nerves in the upper extremities, which were normal in this patient.

\section{Lesion at the level of the nerve root}

Dysfunction at the level of the nerve root, if affecting multiple levels at the lumbosacral region, would explain the asymmetric lower extremity weakness but not the symmetric distal lower extremity numbness.

The combination of distal lower extremity sensory loss and asymmetric weakness involving different myotome levels (L2/L3/L4 for the proximal lower extremity muscles and L5/ S1 for the distal lower extremity muscles) is suggestive of involvement of both lower extremity peripheral nerves and lumbosacral nerve roots, respectively.

\section{Question for consideration}

1. What investigations may help establish a topographic diagnosis?

GO TO SECTION 3 


\section{Section 3}

We pursued a workup that would evaluate both the nerve roots and peripheral nerves: a lower thoracic/lumbar spine MRI with contrast and EMG and nerve conduction studies (NCS).

Routine sensory (right median digit II nerve, right ulnar digit V nerve, and sural nerves) and motor studies (right median nerve, right ulnar nerve, peroneal nerves, and right tibial nerve) were performed. Sensory studies were normal except for absent responses in both sural nerves. Motor studies showed no responses in the right peroneal (recording at extensor digitorum brevis) and tibial nerves. The peroneal nerves recording at the tibialis anterior showed low amplitudes with normal latencies and velocities. The median and ulnar responses were normal except for slightly low median nerve amplitude.

EMG was performed recording in distal and proximal lower limb muscles (L3-S1), right lumbar paraspinals, and distal right upper limb (C8/T1). The right lower limb and lumbar paraspinals showed active denervation (fibrillations and positive sharp waves) in the anterior tibialis, gastrocnemius, vastus medialis, iliopsoas, and semitendinosus with corresponding chronic neurogenic units and moderately reduced recruitment to absent voluntary activity. The vastus medialis and gluteus medius showed too low a rate of activation to determine pattern. The left anterior tibialis and gastrocnemius showed similar findings of active denervation and chronic neurogenic units with markedly reduced recruitment. The patient was not able to tolerate EMG of the left vastus medialis. The right first dorsal interosseus muscle showed normal findings.

These findings suggested an axonal sensorimotor peripheral polyneuropathy and asymmetric bilateral denervation of lumbosacral roots (L2-S1 on the right, L5-S1 on the left). Concomitant denervation in the paraspinal muscles suggested nerve root involvement while specific myotome involvement was determined by the specific distal limb muscles tested.

The spine MRI (figure) showed spondylosis and MM of the involved vertebral bodies along with chronic L3-L4 compression fractures but failed to show spinal cord signal changes or compression or cauda equina enhancement. Notably, the spondylotic changes, including spinal canal and foraminal stenoses, were believed not to explain the patient's neurologic deficits or the degree of denervation suggested by the EMG/
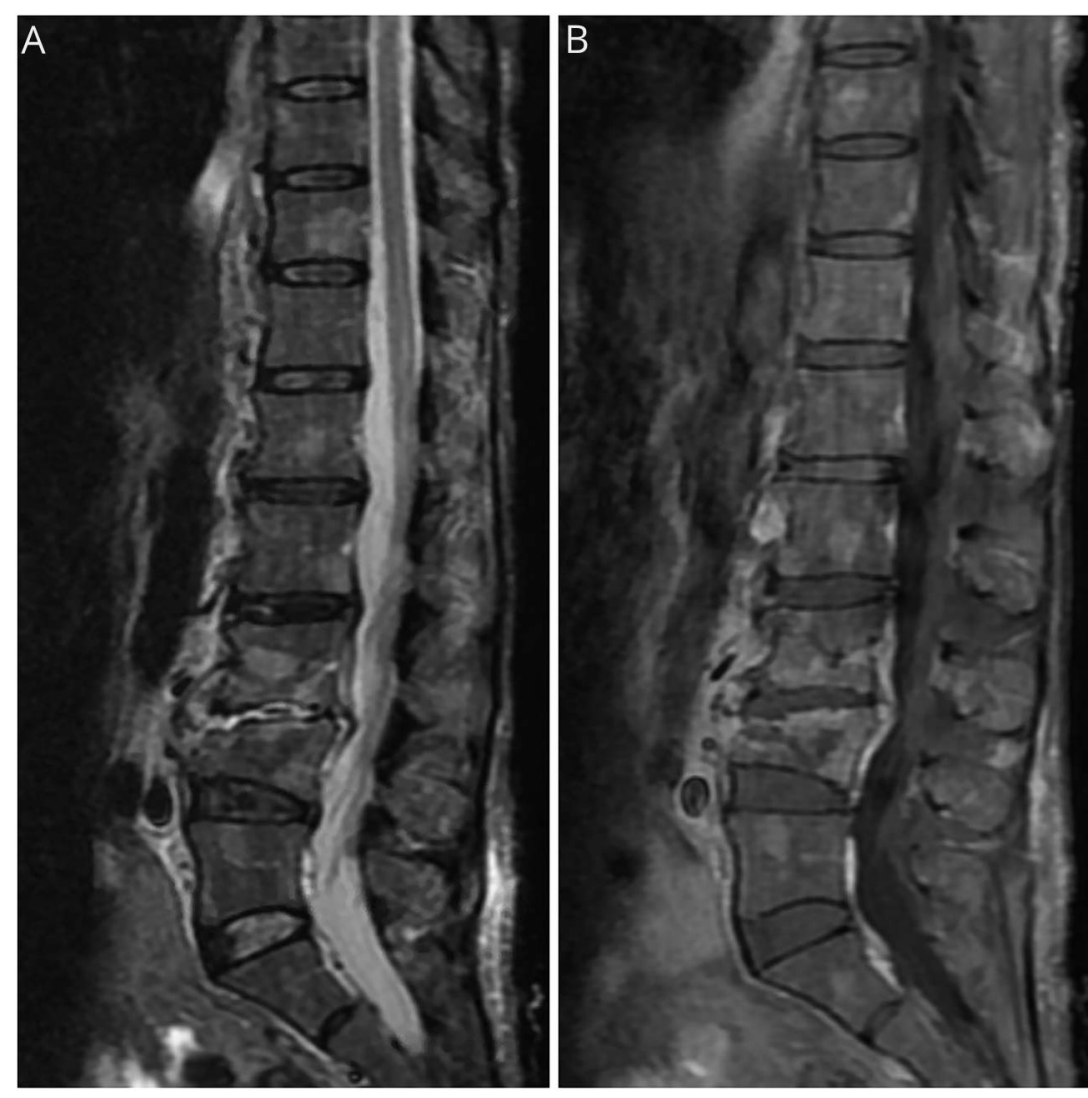

Sagittal short tau inversion recovery (STIR) (left) and postcontrast sagittal T1 (right) show multiple contrast-enhancing, STIR-hyperintense lesions throughout the spine along with pathologic compression fractures of the L3 and L4 vertebral bodies compatible with multiple myeloma of the spine. There are diffuse degenerative changes featuring multilevel spinal canal and foraminal stenosis. There is no evidence of abnormal spinal cord signal or compression. 
NCS. Neuroimaging thus ruled out a mechanical etiology for the diffuse nerve root involvement.

We confirmed our clinical suspicion and established 2 concurrent topographic diagnoses: peripheral polyneuropathy and nonmechanical bilateral lumbosacral polyradiculopathy.

\section{Question for consideration}

1. What are the relevant etiologic differential diagnoses?

GO TO SECTION 4 


\section{Section 4}

One should take into consideration the patient's relevant medical history, including the MM and its ongoing treatment with bortezomib, when considering etiologic differential diagnoses.

Peripheral neuropathy may have multiple causes, the most common being diabetes; however, in the reported patient, the causes are narrowed due to its subacute on chronic nature and the underlying malignancy. Peripheral neuropathy in patients with MM may be secondary to MM itself (paraproteinemic), MM medications (such as bortezomib and thalidomide), amyloidosis, and POEMS syndrome (polyneuropathy, organomegaly, endocrinopathy, M-protein, and skin changes). ${ }^{3-6}$

Radiculopathy in patients with MM is more common than neuropathy and is typically due to direct compression of the nerve roots by plasmacytomas, foraminal stenosis due to pathologic fracture, vertebral body collapse, and, less commonly, leptomeningeal disease (LMD).
Subsequent investigations comprised serologic tests, CSF analysis, fat pad biopsy, and bone marrow stain. Serologic tests were remarkable for normal hemoglobin Alc, thyroidstimulating hormone, and vitamin $B_{12}$, negative $\mathrm{HIV}$, negative angiotensin-converting enzyme (ACE), and normal vascular endothelial growth factor (VEGF) level. Serum electrophoresis revealed a monoclonal peak in the gamma range (IgG lambda) of $11.45 \mathrm{~g} / \mathrm{dL}$.

CSF studies demonstrated normal white and red cell count and glucose, but increased protein $(148 \mathrm{mg} / \mathrm{dL})$; infectious tests (herpes simplex virus, venereal disease research laboratory, West Nile, tuberculosis PCR, cultures) and ACE were negative or within normal limits. CSF cytology and flow cytometry were negative. CSF electrophoresis showed gamma globulin of $62 \%$ (normal 3\%-13\%) and an M-spike of $58.8 \%$ (normally undetectable). Fat pad biopsy and bone marrow stain were negative for amyloid deposits.

\section{Question for consideration:}

1. In light of the history, examination, and workup, what is the final diagnosis? 


\section{Section 5}

\section{Bilateral lumbosacral polyradiculopathy}

As discussed above, the most relevant causes of radiculopathy in patients with MM, especially those with advanced disease such as the reported patient, are related to either direct compression of the nerve roots or LMD. Potential structural causes of compression include vertebral pathologic fractures resulting in foraminal stenosis, vertebral body collapse, and plasmacytomas.

The patient underwent spinal imaging and CSF analysis, including cytology and flow cytometry, which excluded mechanical causes of radiculopathy and LMD, respectively. Despite being negative for signs of LMD, CSF analysis revealed paraproteins. Due to the latter and coupled with the fact that the patient had advanced MM, we attributed the bilateral lumbosacral polyradiculopathy to MM-related paraproteinemia.

\section{Axonal sensorimotor peripheral polyneuropathy}

As discussed above, the most relevant causes of peripheral neuropathy in patients with MM, especially those with advanced disease and in treatment with bortezomib, include bortezomib-related peripheral neuropathy (BIPN), primary amyloidosis, POEMS syndrome, and paraproteinemia.

It is well established that peripheral neuropathy is one of the most significant nonhematologic toxicities associated with bortezomib. BIPN is known to be dose-dependent and to occur within the first courses of bortezomib, reaching a plateau at cycle 5. These patients typically present with a painful sensory neuropathy, in a stocking-glove distribution. The clinical hallmark of this entity is neuropathic pain in the fingertips and toes. Although less frequent, motor neuropathy may also occur with bortezomib and generally features mild to severe distal weakness in the lower extremities and affects up to $10 \%$ of patients. In terms of treatment, bortezomib dose reduction and schedule modifications remain the most important interventions. ${ }^{7}$ In this patient, BIPN was deemed less likely due to the degree and pattern of weakness (very severe, both proximal and distal), the absence of pain associated with the distal sensory changes, and the fact that the worsening weakness/numbness started roughly 3 months following bortezomib initiation. Primary systemic amyloidosis, referred to as light-chain amyloidosis, is a plasma cell disorder associated with peripheral neuropathy. Approximately $15 \%$ of this population has peripheral neuropathy, which can be sensorimotor or autonomic, or both. ${ }^{4}$ Typical symptoms include painful symmetric distal sensory neuropathy; weakness may occur, but is less prominent. Amyloidosis-related neuropathy was considered unlikely in our patient because of the prominent motor component and subsequent negative workup with both fat pad biopsy and bone marrow stain.

POEMS syndrome was considered as a possible etiology of the patient's presentation. In this syndrome, the clinical picture is dominated by a chronic, progressive, predominantly motor polyneuropathy along with osteosclerotic bone lesions. From a neuropathy standpoint, these patients present with distal, symmetric lower extremity sensory changes followed by motor involvement; the course is progressive, often with major motor disability. The reported patient did not meet diagnostic criteria for POEMS given the absence of osteosclerotic lesions, normal VEGF levels, and no evidence of Castleman disease. ${ }^{8}$ Therefore, this diagnosis was deemed less likely.

Based on the above, in addition to the presence of advanced $\mathrm{MM}$ and paraproteins in the spinal fluid, we attributed the patient's axonal sensorimotor peripheral polyneuropathy to MM-related paraproteinemia.

The final diagnosis was paraproteinemic polyradiculoneuropathy and the patient was treated with plasma exchange, which was followed by mild motor improvement. Bortezomib was discontinued in case it was contributing to the neuropathy.

\section{Discussion}

Malignant plasma cell dyscrasias are defined as proliferation of a plasma cell clone producing a monoclonal immunoglobulin known as a paraprotein or M-spike. MM is the most frequent condition in this group of disorders. Patients with MM may experience many neurologic complications including radiculopathy and neuropathy. We report a case of MM-related paraproteinemic polyradiculoneuropathy.

Clinically relevant MM-related paraproteinemic neuropathy, which is a heterogeneous entity, is seen in up to $13 \%$ of patients. It is considered to be sensorimotor, demyelinating, or axonal, and is associated with IgG and immunoglobulin A monoclonal heavy chains and kappa more than lambda light chains. Its pathophysiology remains controversial; proposed mechanisms include production of humoral substance by the tumor, deleterious effect of light chain, and humoral immune-mediated response. Treatment of $\mathrm{MM}$ does not improve paraproteinemic neuropathy, and therapies targeted at the neuropathy are not well established. ${ }^{3,4,9}$

Radiculopathy in MM is generally a consequence of either mechanical compression (by, for example, vertebral plasmacytoma, foraminal stenosis due to pathologic fracture, or vertebral body collapse) or LMD. Uncommonly, nerve root involvement has been associated with MM-related polyneuropathy, as seen in previous studies that relied on pathologic examination rather than EMG/NCS data. ${ }^{10}$

This complex case provides an overview of clinical reasoning and a review of MM-related neurologic complications. MM-related paraproteinemic polyneuropathy is not well understood and this condition may feature a strong electroclinical component of polyradiculopathy.

\section{Study funding}

No targeted funding reported. 


\section{Disclosure}

F. Nascimento is a member of the Neurology ${ }^{\circledR}$ Resident \& Fellow Section Editorial Team. R. Gadot, M. Mims, and K. Nunez-Wallace report no relevant disclosures. Go to Neurology.org/N for full disclosures.

Appendix Authors

\begin{tabular}{lll}
\hline Name & Location & Contribution \\
\hline $\begin{array}{l}\text { Ron Gadot, } \\
\text { BSc }\end{array}$ & $\begin{array}{l}\text { Baylor College of } \\
\text { Medicine, } \\
\text { Houston, TX }\end{array}$ & $\begin{array}{l}\text { Designed study, } \\
\text { collected and analyzed } \\
\text { the data, drafted } \\
\text { the manuscript }\end{array}$ \\
\hline $\begin{array}{l}\text { Fábio A. } \\
\text { Nascimento, } \\
\text { MD }\end{array}$ & $\begin{array}{l}\text { Baylor College of } \\
\text { Medicine, }\end{array}$ & $\begin{array}{l}\text { Conceptualized and } \\
\text { designed study, } \\
\text { collected and analyzed } \\
\text { the data, drafted } \\
\text { the manuscript }\end{array}$ \\
\hline $\begin{array}{l}\text { Martha } \\
\text { Mims, MD, }\end{array}$ & $\begin{array}{l}\text { Baylor College of } \\
\text { PhD }\end{array}$ & $\begin{array}{l}\text { Collected and } \\
\text { analyzed the data, } \\
\text { revised the } \\
\text { manuscript }\end{array}$ \\
\hline
\end{tabular}

Appendix (continued)

\begin{tabular}{|c|c|c|}
\hline Name & Location & Contribution \\
\hline $\begin{array}{l}\text { Karen } \\
\text { Nunez- } \\
\text { Wallace, MD }\end{array}$ & $\begin{array}{l}\text { Baylor College of } \\
\text { Medicine, } \\
\text { Houston, TX }\end{array}$ & $\begin{array}{l}\text { Designed study, collected and } \\
\text { analyzed the data, revised the } \\
\text { manuscript, supervised the study, } \\
\text { provided final approval }\end{array}$ \\
\hline
\end{tabular}

\section{References}

1. Brejt N, Berry J, Nisbet A, Bloomfield D, Burkill G. Pelvic radiculopathies, lumbosacral plexopathies, and neuropathies in oncologic disease: a multidisciplinary approach to a diagnostic challenge. Cancer Imaging 2013;13:591-601.

2. England JD, Asbury AK. Peripheral neuropathy. Lancet 2004;363:2151-5161.

3. Kwan JY. Paraproteinemic neuropathy. Neurol Clin 2007;25:47-69.

4. Dispenzieri A, Kyle RA. Neurological aspects of multiple myeloma and related disorders. Best Pract Res Clin Haematol 2005;18:673-688.

5. Cavaletti G, Marmiroli P. Chemotherapy-induced peripheral neurotoxicity. Nat Rev Neurol 2010;6:657-666.

6. Couriel DR, Ricker H, Steinbach M, Lee CJ. Neurologic manifestations of blood dyscrasias. Hematol Oncol Clin North Am 2016;30:723-731.

7. Argyriou AA, Iconomou G, Kalofonos HP. Bortezomib-induced peripheral neuropathy in multiple myeloma: a comprehensive review of the literature. Blood 2008;112:1593-1599.

8. Rajkumar SV, Dimopoulos MA, Palumbo A, et al. International Myeloma Working Group updated criteria for the diagnosis of multiple myeloma. Lancet Oncol 2014;15:e538-548.

9. Chaudhry HM, Mauermann ML, Rajkumar SV. Monoclonal gammopathy-associated peripheral neuropathy: diagnosis and management. Mayo Clin Proc 2017;92:838-850.

10. Victor M, Banker BQ, Adams RD. The neuropathy of multiple myeloma. J Neurol Neurosurg Psychiatry 1958;21:73-88.

\section{COVID-19 and Neurologic Disease: Call for Papers!}

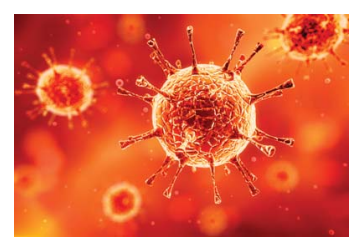

The editors of Neurology are interested in papers that address the neurological aspects of COVID-19 infection and challenges to the management of patients with chronic neurological conditions who have, or are at risk for, the infection. Relevant papers that pass initial internal review will undergo expedited peer review and online publication. We will consider papers posted in preprint servers.

Submit observational studies and clinical trials as Articles and case series and case reports under the Clinical/Scientific Notes category to https://submit.neurology.org/ today!

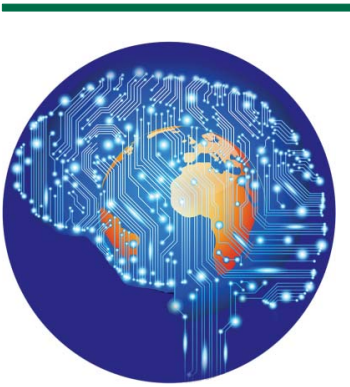

\section{Practice Current: An interactive exchange on controversial topics}

Share your own best practices.

Read commentary with expert opinion.

Explore results on an interactive world map.

NPub.org/NCP/practicecurrent

Neurology ${ }^{\circledR}$ Clinical Practice 


\section{Neurology}

\section{Clinical Reasoning: A 59-year-old woman with multiple myeloma and lower extremity weakness and numbness}

Ron Gadot, Fábio A. Nascimento, Martha Mims, et al. Neurology 2020;94;794-800 Published Online before print April 13, 2020

DOI 10.1212/WNL.0000000000009376

\section{This information is current as of April 13, 2020}

\section{Updated Information \&} Services

References

Subspecialty Collections

Permissions \& Licensing

Reprints including high resolution figures, can be found at: http://n.neurology.org/content/94/18/794.full

This article cites 10 articles, 2 of which you can access for free at: http://n.neurology.org/content/94/18/794.full\#ref-list-1

This article, along with others on similar topics, appears in the following collection(s):

\section{All Neuromuscular Disease}

http://n.neurology.org/cgi/collection/all_neuromuscular_disease MRI

http://n.neurology.org/cgi/collection/mri

Peripheral neuropathy

http://n.neurology.org/cgi/collection/peripheral_neuropathy

Information about reproducing this article in parts (figures,tables) or in its entirety can be found online at:

http://www.neurology.org/about/about_the_journal\#permissions

Information about ordering reprints can be found online:

http://n.neurology.org/subscribers/advertise

Neurology ${ }^{\circledR}$ is the official journal of the American Academy of Neurology. Published continuously since 1951, it is now a weekly with 48 issues per year. Copyright () 2020 American Academy of Neurology. All rights reserved. Print ISSN: 0028-3878. Online ISSN: 1526-632X.

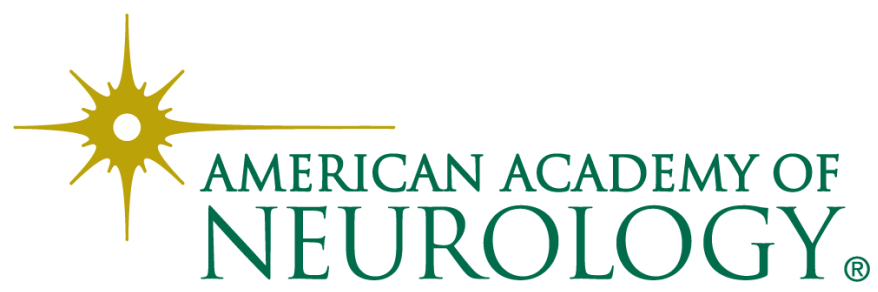

